\title{
Heterogeneity of excision repair cross-complementation group 1 gene expression in non-small-cell lung cancer patients
}

\author{
SERHEY SMIRNOV, ANASTASIYA PASHKEVICH, VALERIYA LIUNDYSHEVA, \\ ANDREY BABENKO and RAISA SMOLYAKOVA \\ Department of Carcinogenesis, Alexandrov N.N. National Cancer Center for Oncology \\ and Medical Radiology, Minsk 223040, Belarus
}

Received July 16, 2014; Accepted August 28, 2014

DOI: $10.3892 / \operatorname{mco} .2014 .415$

\begin{abstract}
Excision repair cross-complementation group 1 (ERCC1) gene expression analysis is currently used widely in the molecular diagnosis of cancer. According to numerous studies, ERCC1 gene expression correlates with overall survival and effectiveness of chemotherapy with platinum agents. However, the degree of this correlation differs among various studies, with certain authors reporting a complete lack of such a correlation. These contradictions may be attributed to a number of factors, including the heterogeneity of the tumor tissue. In this study, we attempted to assess the degree of genetic heterogeneity exhibited by tissue samples obtained from non-small-cell lung cancer (NSCLC) through the expression of the ERCC1 gene. This study included 25 samples of tumor tissue from patients with a morphologically confirmed NSCLC diagnosis. A total of three randomized sections of each specimen were used. The ERCC1 gene expression was assessed by quantitative polymerase chain reaction (qPCR) in the TaqMan format. When planning the experiment and analysis of qPCR data, the MIQE guidelines were taken into consideration. We established that the coefficient of variation of the relative level of ERCC1 gene expression in the majority of the samples exceeded $33 \%(\mathrm{P}<0.05)$, indicating the significant heterogeneity of the sample. We also demonstrated that the degree of heterogeneity of the tumor tissue is largely dependent on disease stage.
\end{abstract}

\section{Introduction}

Non-small-cell lung cancer (NSCLC) is currently the most common type of lung cancer $(1,2)$. Surgical resection remains

Correspondence to: Dr Andrey Babenko, Department of Carcinogenesis, Alexandrov N.N. National Cancer Center for Oncology and Medical Radiology, 2 Agrotown Lesnoy, Minsk 223040, Belarus

E-mail: a.babenko@omr.med.by

Key words: non-small-cell lung cancer, chemotherapy, excision repair cross-complementation group 1, quantitative polymerase chain reaction, expression, heterogeneity the most consistent and successful treatment for NSCLC that has not spread beyond regional lymph nodes. However, $\leq 70 \%$ of patients with lung cancer present with locally advanced or metastatic disease at diagnosis, which significantly complicates subsequent therapeutic interventions (3). The efficiency of treatment for such patients remains low.

Numerous studies suggest the application of platinum- over non-platinum-based therapy as first-line chemotherapy for NSCLC, as suggested by a large volume of data from clinical trials and meta-analyses $(4,5)$. It was demonstrated that the mechanism of action of platinum compounds is associated with the formation of intra- and inter-helix DNA cross-linking, as a result of which the DNA structure is damaged and the replication activity is suppressed $(6,7)$.

One of the critical mechanisms of resistance to platinum-based chemotherapy is the damaged DNA repair mechanism. It is hypothesized that tumor cells with reduced DNA repair ability exhibit a higher sensitivity to treatment, leading to a better outcome following radiotherapy or chemotherapy, whereas an increased repair ability is associated with a poorer therapeutic response and increased tumor resistance (8).

The excision repair cross-complementation group 1 (ERCC1) gene, encoding the corresponding protein, is one of the key links in the chain of intracellular molecular processes responsible for the removal of platinum-induced DNA damage. The ERCC1 gene product belongs to the group of nucleotide excision repair enzymes, which are involved in DNA excision repair by nucleotide removal (9).

A significant volume of evidence has been accumulated, indicating that the survival time of NSCLC patients treated with gemcitabine + cisplatin was reduced through an increase in the ERCC1 gene expression level (10-14).

However, there is a considerable variation of the data currently available in the literature regarding the expression of ERCC1 and other molecular markers obtained through different $(15,16)$ as well as similar methods of analysis $(17,18)$. One of the possible reasons for this inconsistency, along with the presence of several isoforms and the differences in the sensitivity and specificity of the research methods, is intratumoral heterogeneity of mRNA and protein expression (19).

Human tumors often display significant intratumor heterogeneity regarding various characteristics, including histology, 
gene expression, genotype and metastatic and proliferative potential. However, clonal genetic heterogeneity is considered one of the most interesting characteristics, the essence of which is the existence of alternative clones, namely histologically homogeneous tumor tissue expression profiles characterized by different molecular markers. This heterogeneity plays an important role in neoplasia, cancer progression and resistance to treatment (20).

Along with the histological heterogeneity of the investigated sample, intratumoral genetic heterogeneity caused by genome instability in tumors may complicate the molecular classification of tumors into clinically relevant subtypes (21). This may be aggravated by the fact that, for the implementation of the currently available wide range of diagnostic procedures, as a rule, only a small part of the tumor is used. Unfortunately, in the majority of the cases, the data regarding gene expression in the analysis of the tumor site cannot fully characterize the profile of the entire tumor, which may subsequently lead to the selection of inappropriate treatment, early relapse and development of resistance to chemotherapeutic agents.

Numerous studies have demonstrated the genetic heterogeneity of breast cancer tissue $(22,23)$, as well as that of other malignancies (24-26). However, the genetic heterogeneity of lung cancer has yet to be extensively investigated. Thus, the aim of this study was to investigate the heterogeneity of ERCC1 gene expression in NSCLC.

\section{Materials and methods}

Subjects. A total of 25 patients with invasive lung cancer underwent treatment between March, 2013 and February, 2014 at the N.N. Alexandrov National Cancer Center, Minsk, Belarus. The patients comprised 22 men and 3 women, with a median age of 59 years (range, $42-67$ years). The diagnosis of stage 1-3a invasive lung cancer was determined according to the World Health Organization diagnostic criteria (2008) and confirmed by two pathologists. The patient sample included 12 patients with adenocarcinoma, 10 with squamous cell carcinoma and 10 with other types of NSCLC, according to the morphological characteristics of the tumor. None of the patients had received radiotherapy or chemotherapy prior to surgery.

The protocol of the present study was approved by the Institutional Review Board of the Alexandrov N.N. National Cancer Center for Oncology and Medical Radiology (ID no. 20080923) and all the patients provided written informed consent prior to their inclusion in the study.

Samples. All the tumor tissue samples were frozen in liquid nitrogen following resection and pathological examination. The samples were maintained for $<6$ months at $-70^{\circ} \mathrm{C}$. Approximately 20-30 mg of tumor tissue were used for the study. The samples were prepared using a scalpel and weighed on ice prior to placement in lysis solution. All the procedures on the tumor tissue samples and subsequent data analysis were conducted anonymously.

RNA extraction. Total RNA was isolated from fresh-frozen NSCLC tissues using the RNAqueous-4PCR RNA isolation kit (Ambion, Inc., Austin, TX, USA) according to the manu- facturer's protocol, without additional processing by DNase and proteinase. Tissue sample homogenization was performed by special polypropylene microplastics that were supplied with the kit. The degree of contamination of the RNA samples was determined by using agarose gel electrophoresis and by setting up a classical polymerase chain reaction (PCR) with specific oligonucleotide primers for the amplification of the GAPDH gene (data not shown). The concentration and purification of the total RNA fraction was evaluated using a Cary 50 spectrophotometer (Varian Australia Pty Ltd., Melbourne, Australia). RNA integrity was verified using agarose gel electrophoresis without denaturing conditions (data not shown). Tests for the presence of inhibitors of reverse transcription or quantitative PCR (qPCR) were conducted by preparing a series of serial dilutions of RNA samples prior to reverse transcription.

Reverse transcription. Reverse transcription was performed by using the High-Capacity cDNA Reverse Transcription kit (Applied Biosystems, Foster City, CA, USA) according to the manufacturer's protocol. A total of $1 \mathrm{mkg}$ of the total RNA fraction was used per reaction (total volume, $20 \mu \mathrm{l}$ ). The kit working principle is based on using random oligohexamers. After the reverse transcription reaction, the samples were stored for $<1$ month at a temperature between -12 and $-18^{\circ} \mathrm{C}$.

$q P C R$. qPCR was performed using the iQ5 detection system (Bio-Rad Laboratories, Inc., Hercules, CA, USA) and the Maxima HotStartTaq DNA Polymerase kit (Thermo Fisher Scientific Baltics UAB, Vilnius, Lithuania). The total volume of the reaction mix was $25 \mu \mathrm{l}$. We used $50 \mathrm{ng}$ cDNA, $0.5 \mu \mathrm{m}$ of each oligonucleotide, including TaqMan probe for PCR (RNA18S5, 4319413E; ERCC1, Hs01012159_m1; Applied Biosystems, Warrington, UK), $0.2 \mathrm{~mm}$ of each dNTP, $50 \mathrm{~mm} \mathrm{KCl}, 25 \mathrm{~mm}$ Tris- $\mathrm{HCl}, 2 \mathrm{~mm} \mathrm{MgCl}_{2}$ and $1.25 \mathrm{IU}$ HotStartTaq DNA polymerase in the reaction mix. The PCR conditions were as follows: $2 \mathrm{~min}$ at $50^{\circ} \mathrm{C}, 5 \mathrm{~min}$ at $95^{\circ} \mathrm{C}$, followed by 45 cycles for $10 \mathrm{sec}$ at $95^{\circ} \mathrm{C}$ and $60 \mathrm{sec}$ at $60^{\circ} \mathrm{C}$. Measurement of sample fluorescence was performed at the end of each amplification cycle using the FAM channel. ERCC1 gene expression was measured in triplicate and the fold-change of mRNA expression was calculated using the $2^{-\Delta \Delta \mathrm{Ct}}$ method, as described by Livak and Schmittgen (27). The reaction without template was used as the negative control and RNA18S5 as the endogenous control.

Statistical analysis. Statistical analyses were performed using SPSS 23.0 software (SPSS, Inc., Chicago, IL, USA). The Spearman's rank correlation coefficient was used to investigate the correlation between ERCC1 gene expression and clinicopathological characteristics. The Mann-Whitney U test was used to determine the significance of the associations between different sections from the same sample. The Fisher transformation was used to determine the variety coefficient diversity. A two-tailed $\mathrm{P}<0.05$ was considered to indicate a statistically significant difference.

\section{Results}

Evaluation of variation coefficient of gene expression level $(\triangle C p)$ and the relative gene expression level $\left(2^{-\triangle \triangle C p}\right)$ of 
Table I. Distribution of values of the relative level of excision repair cross-complementation group 1 gene expression.

\begin{tabular}{|c|c|c|c|c|}
\hline \multirow[b]{2}{*}{ Stage } & \multirow[b]{2}{*}{ Sample } & \multicolumn{3}{|c|}{ Sections } \\
\hline & & 1 & 2 & 3 \\
\hline \multirow[t]{12}{*}{1} & 1 & + & + & - \\
\hline & 2 & + & + & + \\
\hline & 3 & + & 0 & 0 \\
\hline & 4 & - & 0 & - \\
\hline & 5 & 0 & 0 & 0 \\
\hline & 6 & + & 0 & + \\
\hline & 7 & + & + & + \\
\hline & 8 & 0 & 0 & 0 \\
\hline & 9 & 0 & 0 & 0 \\
\hline & 10 & 0 & 0 & + \\
\hline & 11 & + & + & 0 \\
\hline & 12 & 0 & 0 & 0 \\
\hline \multirow[t]{7}{*}{2} & 13 & - & 0 & 0 \\
\hline & 14 & - & + & + \\
\hline & 15 & 0 & 0 & 0 \\
\hline & 16 & 0 & 0 & 0 \\
\hline & 17 & + & - & + \\
\hline & 18 & 0 & 0 & 0 \\
\hline & 19 & + & + & + \\
\hline \multirow[t]{6}{*}{3} & 20 & 0 & 0 & 0 \\
\hline & 21 & + & + & + \\
\hline & 22 & + & + & + \\
\hline & 23 & 0 & - & - \\
\hline & 24 & 0 & 0 & 0 \\
\hline & 25 & 0 & 0 & 0 \\
\hline
\end{tabular}

+, high level; -, low level; 0, normal.

ERCC1 and RNA18S5. In the present study, we measured the ERCC1 expression levels in 25 samples of human NSCLC. According to BestKeeper v 1.0 software (http://www.genequantification.com/bestkeeper.html), the mean crossing point $(\mathrm{Cp})$ values for the target $(\mathrm{ERCC} 1)$ and the reference (RNA18S5) genes were equal to 31.07 and 15.35, respectively. The target $\mathrm{Cp}$ standard deviation was 3.8 and that of the reference gene 5.0. The target $\mathrm{Cp}$ median value was 31.4 and that of the reference gene 15.0. The values of the coefficient of variation $(\mathrm{CV})$ for one patient in the analysis of three sections were $0-17.6 \%$, with a median of $2.85 \%$. In addition, the values of $\mathrm{CV}$ for the reference gene were $0.61-35.37 \%$, with a median of $5.51 \%$. The mean value of the variation between patients in the sample was $10.94 \%$ for ERCC1 and $54.57 \%$ for RNA18S5. Thus, the internal variation of the ERCC1 and RNA18S5 gene expression based on the total variation in the sample was equal to 41.67 and $15.3 \%$, respectively.

Following normalization $\left(\Delta \mathrm{Cp}=\mathrm{Cp}_{\text {target }}-\mathrm{Cp}_{\text {reference }}\right)$, the values of the target $\mathrm{CV}$ in one sample within the three sections analysis were $1.32-48.1 \%$, with a median of $5.045 \%$. The differences between ERCC1 expression levels were normalized to internal control between sections from one sample, according to the Mann-Whitney U-test in $88 \%$ of the cases (22 patients) $(\mathrm{P}<0.01)$; the differences were not statistically significant in $22 \%$ of the cases (3 patients). Furthermore, all the values were analyzed according to the ERCC1 expression level obtained for normal lung tissue. $\Delta \Delta \mathrm{Cp}$ values $\left(\Delta C \mathrm{p}_{\text {tumor }}-\Delta \mathrm{C} \mathrm{p}_{\text {normal }}\right)$ were calculated for each sample and the relative expression level of the target was calculated according to the $2^{-\Delta \Delta \mathrm{Cp}}$ equation. The CV of target gene expression for the three sections of the same sample ranged between 5.93 and $124.96 \%$, with a median of $52.22 \%$ and a mean value of $53.16 \pm 32.77 \%$. In addition, the $\mathrm{CV}$ value of the ERCC1 relative expression level in two samples was $<10 \%$, in another two samples it ranged between 10 and $20 \%$, in three samples it ranged between 20 and $33 \%$ and 18 patients exhibited levels $>33 \%$.

Heterogeneity of the diagnostic levels of ERCCl gene expression. A detailed data analysis demonstrated that the relative levels of ERCC1 gene expression was high in 12 and low in 6 samples. Overexpression of the target gene in all three sections was detected in only 5 cases. In addition, in 5 patients the level of expression was high in two of the three sections and the remaining 2 patients exhibited overexpression in only one of the three sections. Low levels of ERCC1 gene expression in two of the three sections were identified in 2 patients and in one section in 4 patients. Cases with low levels of ERCC1 gene expression in all three sections from one sample were not identified. The distribution of values of relative expression levels of ERCC1 gene is demonstrated in Table I.

There was no observed statistically significant correlation of the ERCC1 gene expression level with gender, age or histological type of tumor.

\section{Discussion}

A recent study conducted by Sipos et al (28) demonstrated that, when using tumor samples, it is necessary to take into account not only the different clinical characteristic types of variation between different patients, but also intratumoral heterogeneity, including histological heterogeneity of the material, which is determined by getting into excised section other histological types along with tumor tissue. Such variation or heterogeneity may not represent a major issue for experienced pathologists working with modern equipment; however, the genetic heterogeneity of the tumor is a major concern. Bedard et al (29) demonstrated that the genetic heterogeneity of the tumor may be responsible for the development of drug resistance due to the presence of several subpopulations with different gene expression profiles in histologically homogeneous material. Following partial tumor reduction due to elimination of drug-sensitive cells, the risk of early relapse and development of drug resistance (by generalization of minor clones with alternative gene expression profiles) becomes higher. Thus, intra- and intertumoral heterogeneity are crucial in determining the treatment strategy for patients with NSCLC and other nosological types of cancer.

Our results demonstrated that intratumoral ERCC1 and RNA18S5 expression in lung cancer tissue is heterogeneous, with minor changeability of variation series for Cp ERCC1 and RNA18S5 values in one patient (median $<10 \%$ ). The CV 
of the ERCC1 relative expression level directly used in the diagnosis in three sections from a single sample in the majority of the patients was $>33 \%(\mathrm{P}<0.01)$, reflecting the heterogeneity of this sample. Thus, for acquiring exact data on the relative expression of ERCC1, particularly in the field of border values, it is necessary to analyze several biopsies from one sample.

Following the MIQE recommendations (30) in a molecular-genetic analysis using qPCR may cause expression variation of ERCC1 in the samples, first due to the clonal heterogeneity of the tumor, with different clones of malignant cells expressing molecular markers at various levels (31). Second, we should take into account the alterations of tumor and normal tissue, such as normal tissue cells contaminating the section, thus distorting the results. These factors may be included in the concept of common genetic heterogeneity of the tumor. Detecting subpopulations of minor clones with alternative gene expression profiles may help determine the optimal scheme of neoadjuvant and adjuvant chemo- and radiotherapy and reduce the risk of early disease relapse (recurrence) and resistance to treatment. It is also important to determine the exact number of sections for analyzing gene expression level in each specific case. Numerous studies demonstrated that ERCC expression is significantly correlated with indicators of overall survival in patients with NSCLC and with a common prognosis and response to chemotherapeutic intervention $(6,32,33)$. In accordance with our results, the main task of diagnosis in this case was not merely an objective evaluation of the relative ERCC1 expression level, but also a detailed examination of clonal tumor components, i.e., assessment of the genetic heterogeneity of the tumor. Detecting ERCC1 overexpression even in a single section may effectuate significant adjustments in the selection of a treatment strategy using platinum drugs. One should also take into consideration that, when a larger number of sections exhibits similar results, a more appropriate treatment strategy may be selected. The presence of overexpression even in one out of three or five sections proves that it is necessary to investigate the molecular profile of these samples in more detail using combined treatment.

According to the obtained results, we may select one of the possible approaches to calculate the required number of random sections. If we accept results from three sections as $100 \%$ reliable data, using ERCC1 gene expression data from one section allows for detection of $66.5 \%$ of overexpression and $57 \%$ of underexpression; and from two sections, 85.7 and 92\%, respectively. Each section thereafter reduces the risk of false-negative results; however, successive sections increase the possibility of detecting a lower percentage of expression. A detailed analysis of the results of sampling shows that, at the first stage of disease, $\sim 57 \%$ of ERCC1 overexpression is detected in one section, but with two sections the detectability percentage may increase up to $87 \%$. However, we may detect $66 \%$ overexpression from one section and $100 \%$ from two sections in patients at the second stage of the disease. We did not identify any statistically significant differences for the second stage of disease between two and three sections. Finally, in patients at the third stage of the disease, ERCC1 overexpression, if present, may be detected in $100 \%$ of the cases with a single section. Thus, we may be able to estimate the required number of biopsies necessary for detecting some minimum overexpression, i.e., $95 \%$, but other studies must be priorly conducted, including several sections.
The increase in tumor homogeneity according to the ERCC1 expression level criterion from the first to the third stage may be explained by the higher histological homogeneity of the samples at the third stage (without normal tissue included in the analysis), as well as by the higher genetic homogeneity, ensued by the presence of a strongly dominant clone. Based on our data we may provide a possible explanation for the worse prognosis of the third stage in terms of molecular biology. Along with the ability to metastasise, larger tumor size and other pathogenetic factors, we may have to take into consideration the hiding of minor clones by dominant cell clones. Thus, during the early stage of the disease, a few histologically homogeneous populations of clones may be formed by mutations and the high proliferative activity of tumor cells. With disease progression, there may occur a generalization of a dominant (in condition of a specific organism) clone and hiding of minor clones. Following elimination of the dominant clone and a course of chemotherapy, minor clones may become dominant, as they are resistant to the administered drugs. This may result in early or late relapse and reduce the efficiency of chemotherapy.

\section{Acknowledgements}

We would like to thank Dr Vyacheslav Kurchin and Aleksey Kurchenkov at the N.N. Alexandrov National Cancer Center for providing expert technical assistance. This study was supported by the M13-012Lit grant for fundamental research program (2013-2014) from the Belarusian Republican Foundation for Fundamental Research, Belarus.

\section{References}

1. Spyratos D, Zarogoulidis P, Porpodis K, et al: Preoperative evaluation for lung cancer resection. J Thorac Dis 6 (Suppl 1): S162-S166, 2014

2. Sculier JP, Meert AP and Berghmans T: Updates in oncology. Eur Respir Rev 23: 69-78, 2014.

3. Molina JR, Yang P, Cassivi SD, Schild SE and Adjei AA: Non-small cell lung cancer: epidemiology, risk factors, treatment, and survivorship. Mayo Clin Proc 83: 584-594, 2008.

4. Barlesi F, Pujol JL and Daures JP: Should chemotherapy (Cx) for advanced non-small cell lung cancer (NSCLC) be platinum-based? A literature-based meta-analysis of randomized trials. J Clin Oncol 23: 7213, 2005.

5. D'Addario G, Pintilie M, Leighl NB, Feld R, Cerny T and Shepherd FA: Platinum-based versus non-platinum-based chemotherapy in advanced non-small-cell lung cancer: a meta-analysis of the published literature. J Clin Oncol 23: 2926-2936, 2005.

6. Yan D, Wei P, An G and Chen W: Prognostic potential of ERCC1 protein expression and clinicopathologic factors in stage III/N2 non-small cell lung cancer. J Cardiothorac Surg 8: 149, 2013.

7. Leibeling D, Laspe $P$ and Emmert S: Nucleotide excision repair and cancer. J Mol Histol 37: 225-238, 2006.

8. Fuertes MA, Castilla J, Alonso C and Perez JM: Cisplatin biochemical mechanism of action: from cytotoxicity to induction of cell death through interconnections between apoptotic and necrotic pathways. Curr Med Chem 10: 257-266, 2003.

9. Sakano S, Ogawa S, Yamamoto Y, Nishijima J, Miyachika Y, Matsumoto H, Hara T and Matsuyama H: ERCC1 and XRCC1 expression predicts survival in bladder cancer patients receiving combined trimodality therapy. Mol Clin Oncol 1: 403-410, 2013.

10. Rosell R, Taron M, Camps C and Lopez-Vivanco G: Influence of genetic markers on survival in non-small cell lung cancer. Drugs Today (Barc) 39: 775-786, 2003.

11. Bergot E, Levallet G, Campbell K, Dubois F, Lechapt E and Zalcman G: Predictive biomarkers in patients with resected non-small cell lung cancer treated with perioperative chemotherapy. Eur Respir Rev 22: 565-576, 2013. 
12. Gurubhagavatula S, Liu G, Park S, Zhou W, Su L, Wain JC, Lynch TJ, Neuberg DS and Christiani DC: XPD and XRCC1 genetic polymorphisms are prognostic factors in advanced non-small-cell lung cancer patients treated with platinum chemotherapy. J Clin Oncol 22: 2594-2601, 2004.

13. Bradley J, Graham MV, Winter K, Purdy JA, Komaki R, Roa WH, Ryu JK, Bosch W and Emami B: Toxicity and outcome results of RTOG 9311: a phase I-II dose-escalation study using three-dimensional conformal radiotherapy in patients with inoperable non-small-cell lung carcinoma. Int J Radiat Oncol Biol Phys 61: 318-328, 2005.

14. Lord RV, Brabender J, Gandara D, et al: Low ERCC1 expression correlates with prolonged survival after cisplatin plus gemcitabine chemotherapy in non-small cell lung cancer. Clin Cancer Res 8 : 2286-2291, 2002.

15. Lee MR, Cho SH, Kim DC, Lee KC, Lee JH, Kwon HC, Lee HW and Lee SE: Concordance between immunohistochemistry and FISH (fluorescence in situ hybridization) \& SISH (silver in situ hybridization) for assessment of the HER2. Cancer Res 72 (Suppl 3): PD02-PD06, 2012.

16. Besse B, Olaussen KA and Soria JC: ERCC1 and RRM1: ready for prime time? J Clin Oncol 31: 1050-1060, 2013.

17. Friboulet L, Olaussen KA, Pignon JP, et al: ERCC1 isoform expression and DNA repair in non-small-cell lung cancer. N Engl J Med 368: 1101-1110, 2013.

18. Chang MC: Letter to the editor regarding 'Seol H, Lee HJ, Choi Y, et al: Intratumoural heterogeneity of HER2 gene amplification in breast cancer: its clinicopathological significance'. Mod Pathol 26: 609-610, 2013

19. Bachtiary B, Boutros PC, Pintilie M, et al: Gene expression profiling in cervical cancer: an exploration of intratumor heterogeneity. Clin Cancer Res 12: 5632-5640, 2006.

20. Michor F and Polyak K: The origins and implications of intratumor heterogeneity. Cancer Prev Res (Phila) 3: 1361-1364, 2010.

21. Burrell RA, McGranahan N, Bartek J and Swanton C: The causes and consequences of genetic heterogeneity in cancer evolution. Nature 501: 338-345, 2013

22. Merlo LM and Maley CC: The role of genetic diversity in cancer J Clin Invest 120: 401-403, 2010
23. Ng CK, Pemberton HN and Reis-Filho JS: Breast cancer intratumor genetic heterogeneity: causes and implications. Expert Rev Anticancer Ther 12: 1021-1032, 2012.

24. Anaka M, Hudson C, Lo PH, Do H, Caballero OL, Davis ID, Dobrovic A, Cebon J and Behren A: Intratumoral genetic heterogeneity in metastatic melanoma is accompanied by variation in malignant behaviors. BMC Med Genomics 6: 40, 2013.

25. Losi L, Baisse B, Bouzourene H and Benhattar J: Evolution of intratumoral genetic heterogeneity during colorectal cancer progression. Carcinogenesis 26: 916-922, 2005.

26. Saeki R, Nagai H, Kaneko S, Unoura M, Yamanaka N, Okamoto E, Kobayashi K and Matsubara K: Intratumoral genomic heterogeneity in human hepatocellular carcinoma detected by restriction landmark genomic scanning. J Hepatol 33: 99-105, 2000.

27. Livak KJ and Schmittgen TD: Analysis of relative gene expression data using real-time quantitative PCR and the $2^{-\Delta \Delta C}$ method. Methods 25: 402-408, 2001.

28. Sipos F, Constantinovits M and Múzes G: Intratumoral functional heterogeneity and chemotherapy. World J Gastroenterol 20 : 2429-2432, 2014.

29. Bedard PL, Hansen AR, Ratain MJ and Siu LL: Tumour heterogeneity in the clinic. Nature 501: 355-364, 2013.

30. Bustin SA, Benes V, Garson JA, et al: The MIQE guidelines: minimum information for publication of quantitative real-time PCR experiments. Clin Chem 55: 611-622, 2009.

31. Greaves M and Maley CC: Clonal evolution in cancer. Nature 481: 306-313, 2012

32. Jian-Wei B, Yi-Min M, Yu-Xia S and Shi-Qing L: Expression levels of ERCC1 and RRM1 mRNA and clinical outcome of advanced non-small cell lung cancer. Pak J Med Sci 29: 1158-1161, 2013.

33. Yamashita F, Azuma K, Yoshida T, Yamada K, Kawahara A, Hattori S, Takeoka H, Zaizen Y, Kawayama T, Kage M and Hoshino T: Prognostic value of EGFR mutation and ERCC1 in patients with non-small cell lung cancer undergoing platinum-based chemotherapy. PLoS One 8: e71356, 2013. 